\title{
Immune Properties Corroborated by A. Rubens Sea Star Igkappa Gene
}

\author{
Leclerc $\mathrm{M}^{1^{*}}$ and Otten $\mathrm{P}^{2}$ \\ 1556 Rue Isabelle Romée, Sandillon, France \\ ${ }^{2}$ Fasteris $\mathrm{CH}-1228$, Plan-les-Ouates, Switzerland
}

*Corresponding author: Leclerc M, 556 rue Isabelle Romée, 45640 Sandillon (France), Tel: 023841 02 09, E-mail: mleclerc45@gmail.com

Citation: Leclerc M, Otten P (2014) Immune Properties Corroborated By A. Rubens Sea Star Igkappa. SAJ Biotechnol 1: 104. doi: 10.18875/2375-6713.1.104

Article history: Received: 11 June 2014, Accepted: 17 July 2014, Published: 18 July 2014

\section{Abstract}

The sea star Igkappa gene was showing 2 Ig sites after its (star sea) immunization to Horse- radish peroxides (HRP), observed in $2013-14$. The gene showed a specific immune response to the enzyme HRP after its insertion in an Escherichia coli plasmid.

Keywords: Sea star IgKappa gene; Plasmid; Enzymatic assay; Immune reaction

\section{Introduction}

The general idea that emerged from the experiments, made in our laboratoires, was that Echinodermata, as exemplified by sea stars: Asterina gibbosa and Asterias Rubens, possessed an immune system, with B cell lymphocytes, able to mount cellular and humoral-specific responses, after stimulation with a foreign antigen [1]. Asterias Rubens produced "An antibody" anti HRP after injections to HRP, it was shown to correlate to kappa genes, in 2011 [2]. In 2013-2014 a sea star Ig Kappa gene to HRP was cloned $[3,4]$. This gene of which, here is the sequence

5'tGACTGCTGCTATGCGTGGCAACATGGCGTCTCTATGGATGTTCTTCTTTGTCgTGGGGATAACTTTACAACGGAGT TTGGCGATTTACACGTTTCGCGAGCAACCGTCGGACACTAGCGCGTTGCAGGGGAGCACAGTGGTGCTTCACTGCT CCGTTGAGCAGTACATAAACACCACGGCCATCGTTTGGTGGAGCCGTGACTCGGTCATCAGCCACAACAAAGACCTG AAACTGTCCAGTCTAAACACCGACCAGCTCCAAAGGTACTCGATTTCAGGCGACGCATCTCGGGGGGAATTCAACCT TAAAATAGTGAACTTTACCGNCACAGACGCCGCCAGTTACCGCTGTCAGATGTTTGCGA3'.

But a question desserves to be put: did the cloned gene keep the property to induce a specific immune response managed specifically against the used antigen namely HRP (Horse-radish Peroxydase)? It is the object of this work which required, in the first place to make an Escherichia coli plasmid and secondarily to perform an enzyme assay by the contribution of its substratum, to see if the "antibody" is bound in the HRP antigen.

\section{Materials and Method}

\section{Animals}

As precedently [3] we used sea stars immunized to HRP and their transcriptome.

\section{Plasmid construction}

GZK-2SMART cDNA was amplified in standard PCR conditions using primers 5'TAAGGATCCTATGCGTGGCAACATGGCGT and 5'TATAAGCTTACGCAAACATCTGACAGCGG. PCR-amplified DNA was treated with restriction enzymes BamH I and Hind III and inserted into the corresponding sites of pTR-HIS (Life technologies). Final construction was checked by sequencing. The sonication of control E. coli cultures and treated E. coli ones were performed with a sonicator (VIBRACELL 75115). Control lysates and treated lysates were obtained and placed in PBS.

\section{Plasmid construction}

Dosage of Horse-radish peroxydase was performed in microtitration plaque. Control and treated lysates were incubated in presence 
of 50 $\mu \mathrm{l} \mathrm{HRP/} \mathrm{well.} \mathrm{Endogenous} \mathrm{peroxydase} \mathrm{were} \mathrm{studied} \mathrm{and} \mathrm{directly} \mathrm{revealed,} \mathrm{in} \mathrm{controls,} \mathrm{by} \mathrm{ABTS} \mathrm{(3-ethylbenzthiazoline-6-}$ sulfonic acid $+\mathrm{H}_{2} \mathrm{O}_{2}$ ). Experiments were done in duplicate.

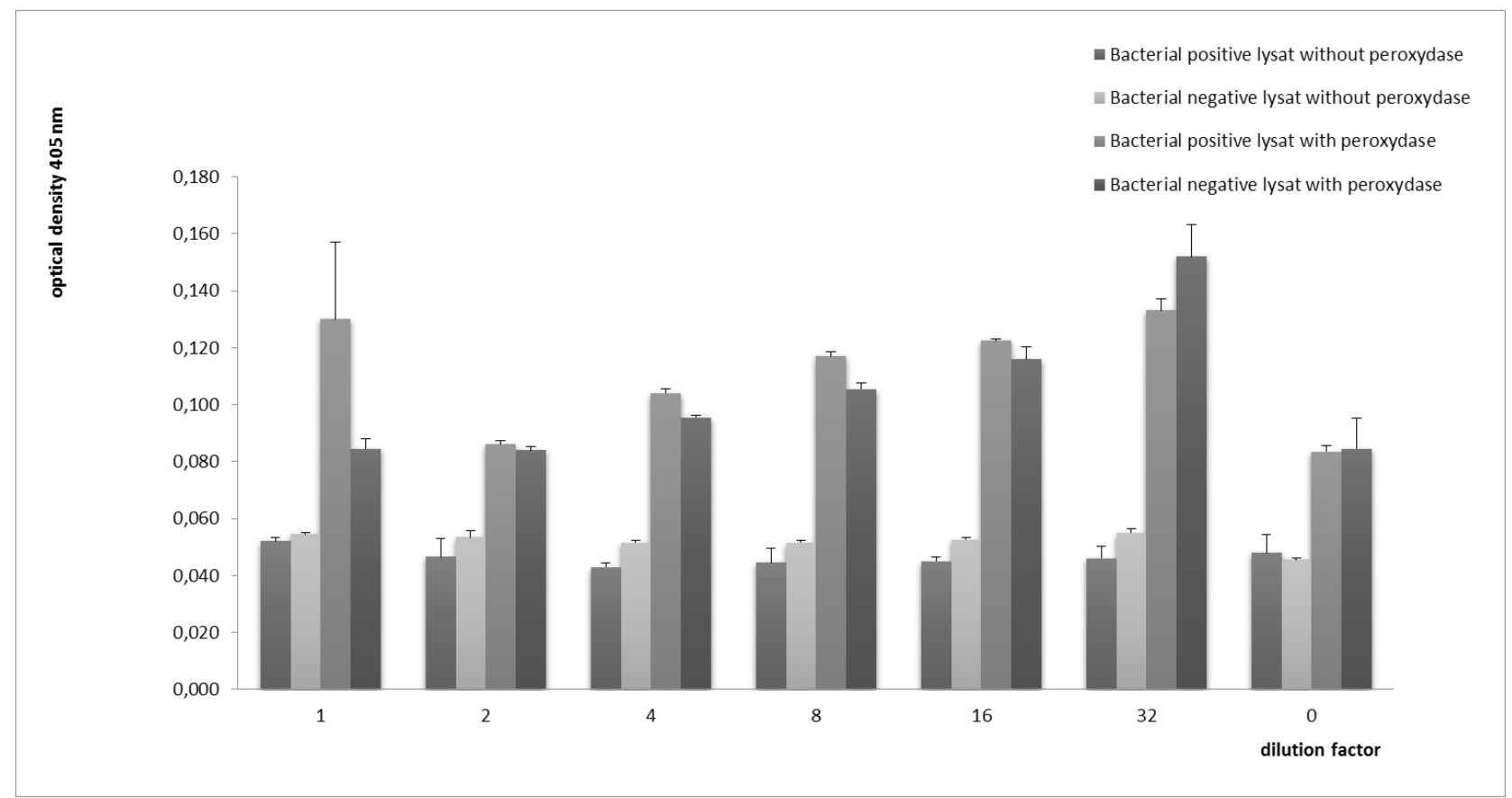

Table 1: HRP " fixation" in control lysates and treated lysates

\section{Results}

The results were summarized in Table 1. The comparison (Table 1) between control lysates (Bacterial positive lysates with peroxydase) and treated ones indicated a significant difference. Optical density at $405 \mathrm{NM}$ in treating lysates showed the presence of bounding peroxydase(HRP), especially at a dilution of 1, in a high degree to that of the controls (controls incubated in the presence or not of HRP).

\section{Dicussion and Conclusion}

Our data showed that the E. coli plasmid, obtained from the sea star IgKappa gene, itself from the immunized sea stars to HRP genome, secretes a primitive antibody which is bound in the HRP antigen. In a general way, E. coli plasmid system may induce antibody [5]. A question deserves to be put, about the complexity of the antigen-binding domain, in invertebrate sea star antibody: this question, for the moment, remains enigmatic. Nevertheless, it can be said that the extracellular junction between two sea star Igkappa chains may play the rôle of Fab. We recall that the primitive sea star antibody would be composed of 4 kappa chains [6].

This deeply moving discovery deserved to be underlined from a point of view of the appearance of antibodies through the evolution of the animal kingdom. This work reveals a true progress in the comprehension of the sea star immune system which includes B and $\mathrm{T}$ sea star lymphocytes, primitive antibody and Igkappa gene. In the present case, when this last (immunized with an antigen) is introduced in an E.coli plasmid, a biological reaction occurs and immune properties are conserved. Itself it is a "revolution" in invertebrate field.

\section{Acknowledgments}

Authors want to thank Pr. Alain Legrand, Stéphanie Rose and Dr. Valérie Quesniau (CNRS Orléans) for their helpful assistance.

\section{References}

1. Leclerc M (1973) Ultrastructural study of the reactions in the axial organ of Asterina gibbosa (echinodermata, asteride) after protein injection. Ann Immunol 124: $363-74$.

2. Leclerc M, Dupont S, Ortega-Martinez O, Hernroth B, Krezdorn N, et al. (2011) Evidence of Kappa genes in the sea-star Asterias rubens (Echinoderma). Immunol Lett 138: 197-8.

3. Leclerc M, Otten P, Osteras M (2013) A True “Candidate Ig Kappa Gene” In The Sea-Star: Asterias Rubens (Echinoderma). Amer J Immunol 9: 75-7.

4. Vincent N, M Osteras, Ottena P, Leclerc M (2014) A new gene in A. rubens: A sea star Ig kappa gene. Meta Gene 2: 320-2.

5. Karu AE, Bell CW, Chin TE (1995) Recombinant Antibody Technology. Ilar J 37: 132-141.

6. Leclerc M (2000) Human kappa-like expression in the axial organ of the sea star Asterias rubens (Echinoderma). Eur J Morph 38: 206-7 